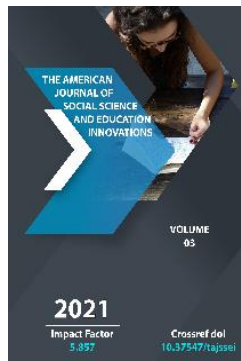

\title{
Preschool Age Children's Fine Motor Skills Development
}

\author{
Mamatova Madina Batiyrovna \\ Lecturer Of The Tashkent State Pedagogical University Named After Nizami, Uzbekistan
}

Journal Website:

http://usajournalshub.c

om/index,php/tajssei

Copyright: Original content from this work may be used under the terms of the creative commons attributes 4.0 licence.

\section{ABSTRACT}

This article discusses the effects of fine hand motor skills in the development of speech in preschool children, the use of finger games.

\section{KEYWORDS}

Motor skills, muscles, finger play, speech, palm activity, corrective effects.

\section{INTRODUCTION}

In the process of preparing children for school education, their preparation for the school program acquires great importance. Because speech is a mean of managing human's brain activities. It manages the processes of memory and cognition, makes it easier to recognize and distinguish subjects. Speech plays an important role in the formation of emotions and an important role in the life of the child and performs the task of communication and mastering experiences. Speech-related skills and experiences are formed during preschool education. "Since language is a means of communication, the word is a scale that 
measures the level and maturity of a person" said the outstanding educator of the Uzbek nation Avloniy [1].

In his work "Majolius - nafois", Alisher Navoi, the great poet, stressed the necessity of teaching our children to speak in their native language beautifully and deeply. Therefore, the proper organization of preschool education for our children is one of the most important issues that parents and educators are thinking about.

One of the most difficult process in the preparation for school education is the normative development of speech. In order to have normal speech it is necessary that the speech centers of the cerebral cortex are fully developed, their sensory organs are also sufficiently developed. In this regard, especially the development of speechbehavioral and speech-hearing analyzers plays an important role. Scientists note that this process is inextricably linked to each other due to the fact that the speech and capillary arm movement centers in the head brain are very close to each other. Therefore, when the fingers of both hands move, the speech Center fades, as a result of which speech develops normally. Thus, in the development of preschool children's speech, it turns out that the capillaries have a peculiar temperament. This is confirmed by scientists who have been studying for many years in the field of preschool education. In this place, the question arises: What is the fine motor skills itself?

\section{MATERIALS AND METHODS}

The concept of "fine motor skills" is deeply studied by a number of Sciences, namely - the sciences of logic, pedagogy, medicine, psychology. Fine motor skills is the movement of the fingers in harmony with the nervous, muscular and bone system.[2] Fine motor skills starts to develop as the child comes into the world. If the child develops fine motor skills in appropriate way, then the speech both develops normally. The child first watches his hand movements, and then learns to control it. Over time, the child begins to perform these actions independently.

In his writings, the great philosopher Aristotle remarked that "the most important weapon in a variety of weapons is the - hand" [2]. Therefore, it helps the child not only with the nervous system, but also with attention, memory and it is closely connected with such psychic processes as contemplation.

German philosopher I.Kanta said in that "the hand is the external appearance of people's brain." in the same way, the movements on the finger are actively involved in the processes of thinking and the development of speech [3]. During the systematization of motor skills, the speech of the child develops. In this place, games that develop a variety of fine motor skills are considered appropriate. Games that develop fingers with children by parents and educators will help to properly organize the process of preschool education, if it is more played. Wishing the child to be educated, clever and resourceful, the parent or educator will not miss the most important period for the child if he draws his attention to exactly such finger games. Because of the child's speech is clear, meaningful, and fluent, and the period of development is exactly what the preschool period is. Games help the child develop fluent speech actively while fine arm movements. It is necessary to plan specific goals for achieving high achievements in the kindergarden. It is 
necessary to create a comfortable programm, which is provided with an object, which develops fine motor skills. Complying with these requirements for the development of fine hand gestures in children.

\section{RESULTS AND DISCUSSION}

An important feature of the organization of educational activities in primary school is the fact that the younger school age is sensitive for the formation of learning motives, the development of stable cognitive needs and interests, which requires a certain "mental" readiness. One of the indicators of intellectual readiness for school education is the level of development of fine motor skills. Usually, a child who has a high level of fine motor skills can reason logically, he has sufficiently developed memory and attention, coherent speech. However, teachers note that firstgraders often have serious difficulties with mastering writing skills. Fine motor skills of the hand in primary school children need and must be developed. An effective means of developing fine motor skills in the educational process are finger games - a kind of exercise for the development of fine muscles of the fingers. They train the accuracy of motor reactions, develop coordination of movements, help to concentrate attention and allows you to verify the presence of the object, its temperature, humidity, and so on. Tapping allows you to get information about the properties of materials. Taking it in your hands allows you to detect many interesting properties of objects: weight, surface features, shapes, etc.

Pressing makes it possible to determine whether the object is soft or hard, what material it is made of. Groping (girth, rubbing, stroking, circular and kneading movements) of small and loose objects (for example, grains, cereals, salt) teaches the child to feel the touch of the palm or fingers. Large, with the index and middle fingers, children touch the details of mosaics, buttons, nuts, coins; large objects are captured with all five fingers. If the object does not fit in the hand, go to two-handed groping-touch: with one hand it is held, fixed, and with the other (leading) - examined. The hand learns, and the brain records sensation and perception, connecting them with visual, auditory and olfactory in complex integrated images and representations. The formation of the skills of touch and fine motor skills occurs in various areas types of subject-practical activities. For example, during technology lessons, fine motor skills are particularly well developed, the muscles of the fingers are strengthened, subtle movements of the hand and fingers are developed, and tactile examination skills are consolidated, especially in the process of modeling from nature. Also very useful for the development of fingers are such activities as application modeling, drawing, making applications, working with scissors, designing from small parts, mosaic, working with stamps.

As L. F. Klimanova notes, for for the development of fingers and various grips, younger students need to draw with colored crayons of various thicknesses. It is important for children to draw with pencils, paint and play with your hands. They should be allowed, first of all, touse various materials that stimulate their tactile and kinesthetic abilities, that is, clay, finger paint, dough,sand and water. Such materials train the hands, making them tense and relax. In order to train the dexterity and mobility of the hands, finger games with singing are effective. Most often, both 
teachers and parents believe that the main thing is exercise and training, training and exercise. Indeed, without exercises and repetitions you can't learn to write. However, as didactics believe, the exercise is appropriate and effective only in the third stage of work; and the first two stages are conscious activity (and not just mechanical exercises). Until the child is not realized, do not understand how to do (not aware of the scheme of action for each individual letters (where to start, where to, where to finish) until the task actions - what to do (for example, a visual image of the letters), exercise the child is not only pointless, but also harmful. "Jumping through the first two stages is not only not promotes the formation of the skill, but slows it down" [4, p. 15].

As practice shows, difficulties arise if the child does not have enough fine motor skills (that is, the ability to control the subtle movements of the fingers and hands). The letters of such children "dance", "climb" for the line, "fall" sideways. Children with undeveloped fine motor skills write very slowly, they have a noticeable tremor when writing, additional strokes, incorrect connections. Handwriting deteriorates even with a slight increase in the speed of writing. These difficulties are better, of course, they are warned before school through a special training session. But even for a first-grader, these exercises will be useful, and someone just needs them.

Psychologists recommend that parents allocate half an hour in the daily routine, but do not do this during the preparation of lessons, and even more so in the educational process. So, B. Volkov says that it is necessary to have a special exercise book, according to which the child will monitor their progress. It is important not to force him to just write as much as possible.

\section{CONCLUSION}

Teachers very often useinteresting and fun tasks that develop hand-eye coordination.For example, you need to draw a pencil path between two sinuous lines without touching them, or circle some drawing, but not along the contour line, but next to it from the inside or outside [1, p. 72]. Komarova T. S. gives a special place to such work as hatching. Initially, stencils with geometric shapes and patterns are used for hatching. Children outline the shapes, and then stroke them not only in parallel segments, but also in waves or circular lines, semi-ovals, loops. Children are very fond of playing "Shadow Theater" (when you fold your fingers in a certain way, you can get images of various animals on the wall).

In short, the importance of fine motor skills in the normal development of speech in preschool children is immeasurable.

\section{REFERENCES}

1. Avloni A. «Turkish gulistan or morality» .- T. Spirituality, 1998.118 p.

2. Antakova L.V. Fomina "Stimulation of speech development in early age children by training finger movements" Abstracts 24.-Moscow, 1974.

3. Kant I. "Wikipedia"

4. Klimanova LF Lessons of a cheerful pencil / LF Klimanov. - Tula: "Rodnichok", 2010. P. 32 